\title{
Dynamic Behavior of Rh Species in Rh/Al2O3 Model Catalyst during Three-Way Catalytic Reaction: An Operando X-ray Absorption Spectroscopy Study
}

\section{$\operatorname{AUTHOR}(\mathrm{S}):$}

Asakura, Hiroyuki; Hosokawa, Saburo; Ina, Toshiaki; Kato, Kazuo; Nitta, Kiyofumi; Uera, Kei; Uruga, Tomoya; ...

Tsukuda, Tatsuya; Teramura, Kentaro; Tanaka, Tsunehiro

\section{CITATION:}

Asakura, Hiroyuki ...[et al]. Dynamic Behavior of Rh Species in Rh/Al2O3 Model Catalyst during Three-Way Catalytic Reaction: An Operando X-ray Absorption Spectroscopy Study. Journal of the American Chemical Society 2018, 140(1): 176-184

\section{ISSUE DATE:}

2018-01-10

\section{URL:}

http://hdl.handle.net/2433/229120

\section{RIGHT:}

This document is the Accepted Manuscript version of a Published Work that appeared in final form in [JournalTitle], copyright (c) American Chemical Society after peer review and technical editing by the publisher. To access the final edited and published work see https://doi.org/10.1021/jacs.7b07114.; The full-text file will be made open to the public on 11 December 2018 in accordance with publisher's 'Terms and Conditions for Self-Archiving'.; この論文は出版社版て ありません。引用の際には出版社版をご確認ご利用ください。;This is not the published version. Please cite only the published version. 


\title{
Dynamic Behavior of $\mathrm{Rh}$ Species in $\mathrm{Rh} / \mathrm{Al}_{2} \mathrm{O}_{3}$ Model Catalyst During Three-Way Catalytic Reaction - An Operando XAS Study
}

\author{
Hiroyuki Asakura, ${ }^{1,2}$ Saburo Hosokawa, ${ }^{1,2}$ Toshiaki Ina, ${ }^{3}$ Kazuo Kato, ${ }^{3}$ Kiyofumi Nitta, ${ }^{3}$ Kei Uera, ${ }^{3}$
} Tomoya Uruga, ${ }^{3,4}$ Hiroki Miura, ${ }^{2,5,6}$ Tetsuya Shishido, ${ }^{2,5,6}$ Jun-ya Ohyama, ${ }^{2,7}$ Atsushi Satsuma, ${ }^{2,7}$ Katsutoshi Sato, ${ }^{2,8}$ Akira Yamamoto, ${ }^{2,9}$ Satoshi Hinokuma, ${ }^{2,10}$ Hiroshi Yoshida, ${ }^{2,10}$ Masato Machida, ${ }^{2,10}$ Seiji Yamazoe, ${ }^{2,11}$ Tatsuya Tsukuda, ${ }^{2,11}$ Kentaro Teramura, ${ }^{1,2}$ Tsunehiro Tanaka ${ }^{1,2, *}$

${ }^{1}$ Department of Molecular Engineering, Graduate School of Engineering, Kyoto University, Kyotodaigaku Katsura, Nishikyo-ku, Kyoto 615-8510, Japan

${ }^{2}$ Elements Strategy Initiative for Catalysts \& Batteries (ESICB), Kyoto University, 1-30 Goryo-Ohara, Nishikyo-ku, Kyoto 615-8245, Japan

${ }^{3}$ Japan Synchrotron Radiation Research Institute, SPring-8, Sayo, Hyogo 679-5198, Japan

${ }^{4}$ Innovation Research Center for Fuel Cells, The University of Electro-Communications, 1-5-1 Chofugaoka, Chofu, Tokyo 182-8585, Japan

${ }^{5}$ Department of Applied Chemistry, Graduate School of Urban Environmental Sciences, Tokyo Metropolitan University, 1-1 Minami-osawa, Hachioji, Tokyo 192-0397, Japan

${ }^{6}$ Research Center for Hydrogen Energy-Based Society, Tokyo Metropolitan University, 1-1 Minami-osawa, Hachioji, Tokyo 192-0397, Japan

${ }^{7}$ Graduate School of Engineering and Institute of Materials and Systems for Sustainability, Nagoya University, Nagoya 4648603, Japan

${ }^{8}$ Department of Integrated Science and Technology, Faculty of Science and Engineering, Oita University, 700 Dannoharu, Oita 870-1192, Japan

${ }^{9}$ Graduate School of Human and Environmental Studies, Kyoto University, Kyoto 606-8501, Japan

${ }^{10}$ Department of Applied Chemistry and Biochemistry, Graduate School of Science and Technology, Kumamoto University, 2-39-1 Kurokami, Chuo, Kumamoto 860-8555, Japan

${ }^{11}$ Department of Chemistry, School of Science, University of Tokyo, 7-3-1 Hongo, Bunkyo-ku, Tokyo 113-0033, Japan

Three-way catalyst, Rh catalyst, Operando, XAS, XANES, EXAFS

\begin{abstract}
The dynamic behavior of Rh species in $1 \mathrm{wt} \% \mathrm{Rh} / \mathrm{Al}_{2} \mathrm{O}_{3}$ catalyst during the three-way catalytic reaction was examined using a micro gas chromatograph, a $\mathrm{NO}_{\mathrm{x}}$ meter, a quadrupole mass spectrometer, and time-resolved quick $\mathrm{X}$-ray absorption spectroscopy (XAS) measurements at a public beamline for XAS, BL01B1 at SPring-8, operando. The combined data suggest different surface rearrangement behavior, random reduction processes, and autocatalytic oxidation processes of Rh species when the gas is switched from a reductive to an oxidative atmosphere and vice versa. This study demonstrates an implementation of a powerful operando XAS system for heterogeneous catalytic reactions and its importance for understanding the dynamic behavior of active metal species of catalysts.
\end{abstract}

\section{INTRODUCTION}

Platinum group metal (PGM) elements such as Rh, Pd, and $\mathrm{Pt}$ are frequently used as essential components of three-way catalysts (TWCs) for purification of harmful gases such as nitrogen oxides $\left(\mathrm{NO}_{\mathrm{x}}\right)$, carbon monoxide $(\mathrm{CO})$, and hydrocarbons (HCs) in automobile exhaust gas. The total demand for Rh, Pd, and Pt for TWCs in 2012 was about $80 \%, 70 \%$, and $40 \%$ of available materials, respectively. ${ }^{1}$ On the other hand, the number of automobiles worldwide reached 1.2 billion by the end of 2014, as reported by the Japan Automobile Manu- facturers Association, Inc., ${ }^{2}$ and has been increasing every year. Further, regulations on exhaust gas emissions have become more restrictive with time. Therefore, the reduction of PGM element use for TWCs has been among the urgent global issues to arise in response to the trend of increasing demand for automobiles worldwide and the need to protect the global environment.

The high demand for Rh for TWCs stems from its outstanding catalytic activity in the reduction of toxic $\mathrm{NO}_{\mathrm{x}}$ to nontoxic nitrogen $\left(\mathrm{N}_{2}\right)$. To reduce $\mathrm{Rh}$ usage for economic and environ- 
mental reasons, it is very important to understand the fundamental behavior of $\mathrm{Rh}$ species (i.e., oxidation, reduction, aggregation, etc.) under working conditions, or operando. Although an enormous number of studies have already been performed on the mechanism of catalysis, degradation, and regeneration of Rh-based TWCs for several decades, ${ }^{3}$ further research is still needed.

The term operando, or especially operando spectroscopy, is a generic concept describing application of spectroscopic techniques to materials in their working state (e.g., a catalyst at work) to elucidate the relationships among function, structure, and/or the electronic states. Researchers generally study the relationships between the catalytic performance and dynamic behavior of TWCs using various gas molecules. For this purpose, IR spectroscopy has been one of the most widely used techniques to clarify the catalysis mechanism by identifying the intermediate adsorbed species on catalysts. ${ }^{4}$ However, IR spectroscopy can observe only gaseous or adsorbed molecules. The dynamic behavior of catalytically active metal species at very high temperature and under both oxidative and reductive atmospheres are of interest to understand the true active sites for catalysis such as three-way catalysis.

For example, so-called in situ or environmental transmission electron microscopy (TEM) is an emerging technique to directly observe small targets such as PGM nanoparticles on supports under a very low-pressure environment. ${ }^{5}$ However, the applicable pressure is usually much lower than atmospheric pressure, which is far from the realistic conditions for TWCs. Among various analytical techniques, X-ray spectroscopy has been most successfully applied for in situ studies, especially for reactions under harsh conditions such as threeway catalysis. The most common analytical technique that utilizes X-rays as a probe is X-ray diffraction (XRD). XRD is a powerful technique for reaction monitoring under both common, ex situ conditions and in situ conditions because of its penetrating power. For example, Jozwiak et al. studied the reduction behavior of iron oxides with hydrogen or carbon monoxide by an in situ XRD technique in combination with conventional temperature-programmed reduction and thermogravimetry-differential thermal analysis techniques, and clarified the temporal variation of the composition of iron oxide species. ${ }^{6}$ Bao et al. used in situ $\mathrm{XRD}^{7-8}$ to elucidate the effect of confinement of iron oxides in carbon nanotubes on their activity in Fischer-Tropsch synthesis. ${ }^{9}$ However, the particles sizes of the metal species in these cases are typically around or no less than $10 \mathrm{~nm}$. The XRD technique is inherently unsuitable for sensitive analysis of very small particles (sizes less than a few nanometers). Thus, monitoring $\mathrm{Rh}$ species that exist in $1 \mathrm{wt} \% \mathrm{Rh} / \mathrm{Al}_{2} \mathrm{O}_{3}$ is usually outside the scope of the XRD technique.

On the other hand, X-ray absorption spectroscopy (XAS) can be utilized to study the redox behavior and structural changes of such very small species. In principle, XAS also has a high penetrating power and element specificity. A high degree of freedom for the sample environment enables the combination of XAS with other spectroscopic techniques such as IR spectroscopy. For example, Newton et al. at the European Synchrotron Radiation Facility, Grenoble, France, in association with various research groups, extensively applied operando spectroscopy in combination with XAS and other techniques [e.g., diffuse reflectance infrared spectroscopy (DRIFT)] to various heterogeneous catalysts, especially TWCs and related materials, ${ }^{10-17}$ to study alcohol oxidation for more than a decade. Grunwaldt and Baiker and their colleagues have reported operando XAS studies of Rh and Rh-based catalysts under the methane oxidation reaction even with flow direction or two-dimensional resolution and observed the detailed spatial distribution of the $\mathrm{Rh}$ state at approximately the ignition temperature. ${ }^{18-24}$ These excellent studies focused on the bulk states of PGM species and adsorbed small molecules to understand the elementary reactions and specific dynamic behavior of the catalysts, and have yielded deep insights into the reaction mechanism under well-controlled model conditions.

In this work, the dynamic behavior of Rh species in a model Rh-based catalyst, $1 \mathrm{wt} \% \mathrm{Rh} / \mathrm{Al}_{2} \mathrm{O}_{3}$, under relatively idealized conditions has been extensively studied for the first time by simultaneous quantitative observation of the eluent gas and use of a quick XAS measurement system at a public beamline, BL01B1, at SPring-8. ${ }^{25}$ The different gases were quantified using a micro gas chromatograph (GC), a $\mathrm{NO}_{\mathrm{x}}$ meter, and a quadrupole mass (Q-Mass) spectrometer. We focused on the relationship between the catalytic activity in the reduction of $\mathrm{NO}_{\mathrm{x}}$ species and the surface and bulk dynamics of Rh species to obtain insight into the fundamental attributes of a Rh-based TWC. We found that the reaction steps of oxidation and reduction of surface Rh species involve two-step autocatalytic oxidation by a Finke-Watzky-type nanoparticle formation mechanism and simple one-step pseudo-first-order kinetics.

\section{EXPERIMENTAL DETAILS}

2.1. Preparation of 1 wt $\% \mathbf{R h} / \mathbf{A l}_{2} \mathrm{O}_{3} \cdot \mathrm{Rh} / \mathrm{Al}_{2} \mathrm{O}_{3}$ (1 wt\%) was prepared by a commonly used impregnation method. A portion of $\mathrm{Rh}$ acetylacetonate $(0.08 \mathrm{~g}, 0.02 \mathrm{~g}$ on Rh metal basis) was dissolved in ethyl acetate $(18 \mathrm{~mL})$ in an evaporating dish, and $\gamma-\mathrm{Al}_{2} \mathrm{O}_{3}$ (JRC-ALO-7, $1.98 \mathrm{~g}$ ) was added to the Rh solution. The mixture was heated in a water bath to $80^{\circ} \mathrm{C}$ and continuously stirred with a glass rod to dryness. Subsequently, the dried sample was calcined at $500{ }^{\circ} \mathrm{C}$ for $3 \mathrm{~h}$. All materials except for $\gamma-\mathrm{Al}_{2} \mathrm{O}_{3}$ were purchased from Wako Pure Chemical Industries, Ltd. and used as received. $\gamma-\mathrm{Al}_{2} \mathrm{O}_{3}$ was kindly provided by the Catalysis Society of Japan. Temperature programmed reaction of the three-way catalytic reaction (TWCR) over this catalyst was performed at our laboratory (Figures S1 and S2). We cannot find any evident Rh particles in the asprepared and spent catalysts by TEM measurements (Figure S3).

2.2. XAS measurement. Rh $K$-edge XAS measurements were conducted at a public beamline, BL01B1, ${ }^{25}$ SPring-8 (Japan Synchrotron Radiation Research Institute, Hyogo, Japan). The incident $\mathrm{X}$-rays were monochromatized with a Si(311) double crystal monochromator. Higher harmonic Xrays were removed by setting the glancing angle of the Rhcoated X-ray mirrors to $1.5 \mathrm{mrad}$. The incident $\left(I_{0}\right)$ and transmitted $\left(I_{1}\right)$ X-ray fluxes were measured using ion chambers filled with $\operatorname{Ar}(100 \%)$ and $\operatorname{Ar}(50 \%) / K r(50 \%)$, respectively. Conventional Rh $K$-edge XAS spectra of a Rh metal foil and $\mathrm{Rh}_{2} \mathrm{O}_{3}$ were collected as reference data. $\mathrm{Rh}_{2} \mathrm{O}_{3}$ was mixed with an appropriate amount of boron nitride, pressed into a pellet, and used for XAS measurement. The photon energy was calibrated at the inflection point of the Pd K-edge X-ray absorption near-edge structure (XANES) spectrum of Pd metal foil to 24,350 eV. Data were reduced using the Athena and Artemis software ver. 0.9.25 included in the Demeter package. ${ }^{26}$

Operando XAS measurements were performed at the same beamline, BL01B1, using a high sampling rate thermal con- 
ductivity detector GC (490 Micro GC, Agilent Technologies Inc.) for quantification of $\mathrm{CO}, \mathrm{C}_{3} \mathrm{H}_{6}, \mathrm{~N}_{2}, \mathrm{CO}_{2}, \mathrm{O}_{2}$, and $\mathrm{N}_{2} \mathrm{O}$; a $\mathrm{NO}_{\mathrm{x}}$ meter (ECL-88AO Lite, Anatec Yanaco Inc.) for quantification of $\mathrm{NO}_{\mathrm{x}}$ species; and a Q-Mass spectrometer (BELMass, MicrotracBEL Corp.) for semi-quantitative analysis of the eluent gas. The acquisition time for one XAS spectrum was approximately $3 \mathrm{~min}$. A schematic view of the operando XAS setup is shown in Scheme 1.

Scheme 1. Simplified view of operando XAS setup.

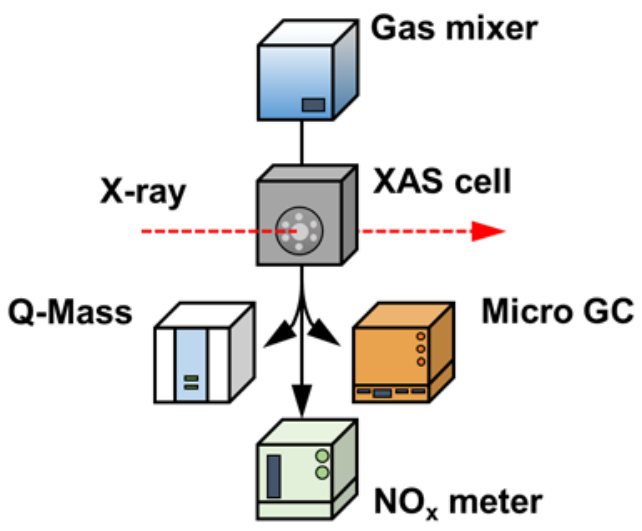

To secure the gas flow path, $200 \mathrm{mg}$ of $1 \mathrm{wt} \% \mathrm{Rh} / \mathrm{Al}_{2} \mathrm{O}_{3}$ (25/50 mesh) was directly pelletized $(\varphi 10 \mathrm{~mm}$, thickness ca. 3 $\mathrm{mm}$ ) inside a modified heating XAS cell (ASPF-20-03, Kyowa Vacuum, Figure S4). The incident X-rays penetrated the center of the sample with a beam size of approximately 4 $\mathrm{mm}$ (horizontal) $\times 1 \mathrm{~mm}$ (vertical). Thus, the observed $\mathrm{Rh}$ state was averaged in the gas flow and X-ray directions. The catalyst was pretreated under He flow at $400{ }^{\circ} \mathrm{C}$ for $30 \mathrm{~min}$. Immediately after pretreatment, the TWCR was tested. The reaction model gas $\left(100 \mathrm{~mL} \mathrm{~min}^{-1}\right)$ contained NO (1000 ppm), $\mathrm{CO}$ (1000 ppm), $\mathrm{C}_{3} \mathrm{H}_{6}$ (250 ppm), $\mathrm{O}_{2}$ (912.5-1337.5 ppm), and He balance. The concentration of $\mathrm{O}_{2}$ was varied between 912.5 and $1337.5 \mathrm{ppm}$ during the reaction. The stoichiometric condition was achieved when the concentration of $\mathrm{O}_{2}$ was set to $1125 \mathrm{ppm}$, on the basis of the chemical equation shown below.

$\mathrm{C}_{3} \mathrm{H}_{6}+4 \mathrm{NO}+4 \mathrm{CO}+9 / 2 \mathrm{O}_{2} \rightarrow 2 \mathrm{~N}_{2}+7 \mathrm{CO}_{2}+3 \mathrm{H}_{2} \mathrm{O}$

For clarity, the lambda parameter is introduced as an indicator of the oxygen concentration or stoichiometric balance:

$$
\lambda=\frac{[\mathrm{NO}]_{a}+[\mathrm{CO}]_{a}+\left[\mathrm{O}_{2}\right]_{a} \times 2}{[\mathrm{NO}]_{s}+[\mathrm{CO}]_{s}+\left[\mathrm{O}_{2}\right]_{s} \times 2}
$$

where $[\mathrm{X}]_{y}$ is the concentration of X in the actual $(y=a)$ or stoichiometric condition $(y=s)$.

The reaction was performed following the oxygen profile illustrated in Figure 1 shown below. First, the leanest gas $(\lambda=$ 1.1) was introduced into the XAS cell, and the $\lambda$ value of the inlet gas was decreased by 0.05 every $20 \mathrm{~min}$ for $1 \mathrm{~h} 40 \mathrm{~min}$ to the richest gas among all the conditions $(\lambda=0.9)$. Subsequently, the $\lambda$ value of the inlet gas was increased in the same manner to 1.1 in another $1 \mathrm{~h} 20 \mathrm{~min}$. After the first lean-rich-lean cycle, the $\lambda$ value was decreased abruptly to 1.0 and 0.9 successively and increased again to 1.0 and then to 1.1 . The reaction time was 4 h 20 min. For clarity, we use a 24 h clock notation as if the reaction started at 0:00, unless otherwise stated.

\section{RESULTS}

In this section, the catalytic activity of $1 \mathrm{wt} \% \mathrm{Rh} / \mathrm{Al}_{2} \mathrm{O}_{3}$ is discussed on the basis of the GC and $\mathrm{NO}_{\mathrm{x}}$ profiles. Subsequently, the dynamic behavior of Rh species is estimated from the temporal variation of a series of XANES spectra, and several selected Fourier transforms of extended X-ray absorption fine structure (EXAFS) spectra with characteristic changes are also discussed. A comprehensive interpretation is given in chronological order in the Discussion section.

3.1. Catalytic activity. Figure 1 shows the eluent gas concentration as quantified by the micro GC at approximately 3 min intervals, the $\mathrm{NO}_{\mathrm{x}}$ meter, and the corresponding profile of $\lambda\left(\mathrm{O}_{2}\right.$ concentration indicator). This overall profile at the XAS beamline, BL01B1, SPring-8, was essentially identical to that recorded at our laboratory (not shown), which ensured that the experiment was indeed performed in operando, at least from the viewpoint of catalytic activity assessment. The sum of the $\mathrm{NO}_{\mathrm{x}}$ species and reduced $\mathrm{N}_{2}$ gas was close to $1000 \mathrm{ppm}$ as the $\mathrm{NO}$ basis throughout the reaction. This means that negligible amounts of other nitrogen-related species such as $\mathrm{N}_{2} \mathrm{O}$ or $\mathrm{NO}_{2}$ were generated, at least under the present high-temperature conditions, which is consistent with the Q-Mass profile (Figure S5). It is evident that the production rate of $\mathrm{N}_{2}$ over $1 \mathrm{wt} \%$ $\mathrm{Rh} / \mathrm{Al}_{2} \mathrm{O}_{3}$ at $400{ }^{\circ} \mathrm{C}$ under lean conditions was less than $100 \%$, at approximately $70 \%-80 \%(0: 00-0: 40)$. Note, however, that the first GC analysis result showed that the $\mathrm{N}_{2}$ concentration just after the gas was introduced (0:03) was slightly higher than that before the first gas switch $(0: 20)$. A gradual change in the amount of $\mathrm{NO}_{\mathrm{x}}$ was also observed initially. In addition, a small amount of $\mathrm{O}_{2}$ was observed in the later stages of the first period $(0: 10-0: 20)$. These results indicate that the $\mathrm{Rh}$ surface was oxidized in the first $10 \mathrm{~min}$ and lost its catalytic activity upon reduction of NO. When the feed gas composition became stoichiometric $(\lambda=1.0)$, or under the rich condition, the NO gas was quantitatively decomposed into $\mathrm{N}_{2}(0: 40$ $2: 20)$. On the other hand, the appearance of $\mathrm{CO}$ and a small decrease in the amount of $\mathrm{CO}_{2}$ in the eluent gas were observed under the rich condition (1:20-2:00). We believe that this phenomenon may be attributed to the water-gas shift reaction (WGSR) after the TWCR was complete, as discussed in the Supporting Information.

After the feed gas composition returned to the lean condition, the production rate of $\mathrm{N}_{2}$ decreased to either $80 \%$ or $60 \%$ (2:20-3:00). In addition, a small amount of $\mathrm{O}_{2}$ gradually appeared (2:40-3:00) under the leanest condition. Gradual changes in the amount of $\mathrm{NO}_{\mathrm{x}}$ were also observed at the points where the feed gas composition was switched from a stoichiometric to a lean condition at around 2:20 or 4:00, and from a lean to a stoichiometric condition at around 3:00 or 4:20. Note that the increase in the amount of $\mathrm{NO}_{\mathrm{x}}$ during the change from stoichiometric to lean conditions exhibited sigmoidal curves and was slower than that during the change from lean to stoichiometric conditions, which may be regarded as an exponential curve. We believe that these phenomena reflect the surface redox behavior of $\mathrm{Rh}$ species.

A detailed kinetic analysis is given in the Discussion section. During the second lean-rich-lean cycle (2:40-4:20), the NO reduction rate increased to approximately $90 \%$ (3:00) and was kept near $100 \%$ before the last lean condition (4:00-4:20), which showed only $60 \%$ conversion from $\mathrm{NO}$ to $\mathrm{N}_{2}$.

In brief, the GC profile for the TWCR over $1 \mathrm{wt} \% \mathrm{Rh} / \mathrm{Al}_{2} \mathrm{O}_{3}$ was identical to that obtained in the laboratory experiment. Furthermore, interesting behavior was observed at each gas 
switching point and under rich conditions. The different pro-

files of the NO reduction rate at the gas composition switching

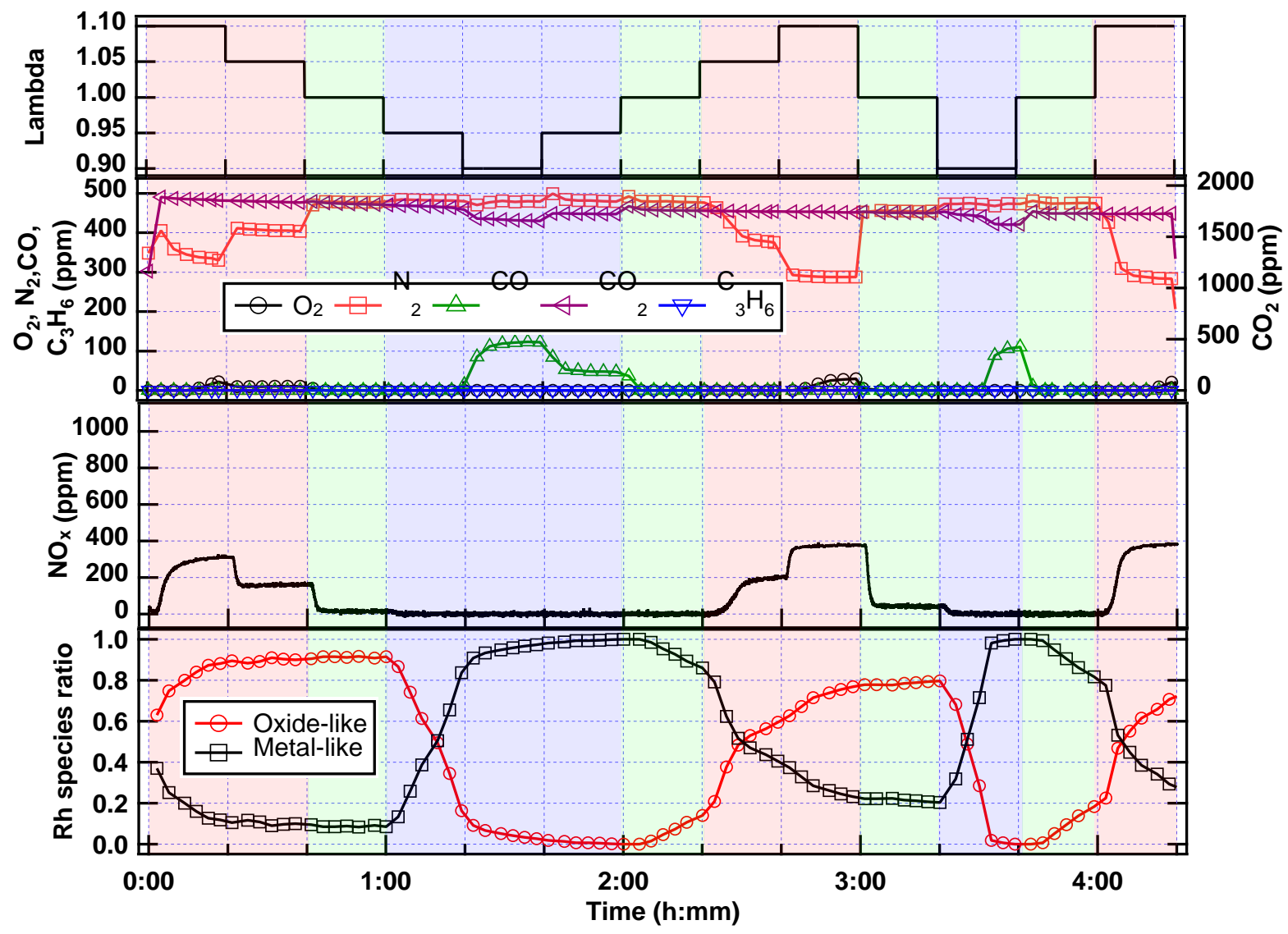

Figure 1. GC and $\mathrm{NO}_{x}$ profiles of the eluent gases and time course of the metallic or oxidized Rh species ratio estimated by linear combination fitting analysis of the Rh $K$-edge XANES spectra during the TWCR over 1 wt\% $\mathrm{Rh} / \mathrm{Al}_{2} \mathrm{O}_{3}$ at $400{ }^{\circ} \mathrm{C}$ during operando XAS measurement, with $\lambda\left(\mathrm{O}_{2}\right.$ concentration) profile. (Note: $\mathrm{N}_{2} \mathrm{O}$ was not observed throughout the reaction.)

points implied dynamic redox behavior of the Rh species.

3.2. Dynamic redox behavior of $\mathbf{R h}$ species. The temporal variation of metallic or oxidized Rh species, as estimated by linear combination fitting (LCF) analysis using a series of $\mathrm{Rh}$ $K$-edge XANES spectra of $1 \mathrm{wt} \% \mathrm{Rh} / \mathrm{Al}_{2} \mathrm{O}_{3}$, is also shown in Figure 1. Note that Figure 1 shows the trend of the redox behavior of the total Rh species, but not the actual redox degree of the Rh species (i.e., $\mathrm{Rh}^{0}$ or $\mathrm{Rh}^{3+}$ ). Linear combination fitting analysis was performed using the initial XANES spectrum before He pretreatment, which represents an oxide-like $\mathrm{Rh}$ species of the calcined $\mathrm{Rh} / \mathrm{Al}_{2} \mathrm{O}_{3}$, and the XANES spectrum of the most reduced state after the second rich condition at around 3:45. We did not use the XANES spectra of Rh foil and bulk $\mathrm{Rh}_{2} \mathrm{O}_{3}$ for the LCF analysis because the XANES spectrum of Rh foil usually does not represent that of the small $\mathrm{Rh}$ nanoparticles discussed here. The complete profile of the Rh $K$-edge XANES spectra and the time course of the metallike or oxide-like $\mathrm{Rh}$ species ratio including the pretreatment step are provided in the Supporting Information (Figures S6 and S7). During pretreatment, the amount of oxide-like Rh species was reduced by $60 \%$. After the lean feed gas was initially introduced, the oxidized Rh species increased rapidly in approximately $10 \mathrm{~min}$, and $90 \%$ of the Rh species were oxidized. After the oxidation process, the electronic state of the average Rh species remained unchanged before the rich condi- tion (0:10-1:00) and even under the stoichiometric condition. However, the introduction of rich feed gas initiated an initially rapid and then slow reduction of the $\mathrm{Rh}$ species (1:00-2:00). This behavior can be interpreted as the occurrence of a gradual reduction process from the surface to the core of the $\mathrm{Rh}$ species. When the feed gas composition was changed to the stoichiometric and lean conditions again, $80 \%$ of the Rh species were gradually oxidized (2:00-3:00). The difference in the oxidation ratio between the first and second lean conditions ( $90 \%$ and $80 \%$, respectively) can be explained by agglomeration of Rh species, which leads to a decrease in the specific surface area under a reductive atmosphere.

In addition, the $\mathrm{R}$ factors obtained by LCF analysis from 2:20 to 3:20 were significantly larger than those in the other periods (Figure S8). This fact implies that the spectral standards used in the LCF analysis may be insufficient; in other words, there may be a third Rh component. Taking into account the aggregation process of Rh species, we can assume the three Rh components to be metal-like Rh, oxide-like Rh on the surface of Rh particles (surface Rh oxide), and oxide-like $\mathrm{Rh}$ in $\mathrm{Rh}$ particles (bulk Rh oxide) in comparison of the standard spectra for LCF with those of Rh metal and $\mathrm{Rh}_{2} \mathrm{O}_{3}$ (Figure $\mathrm{S} 5)$. However, it is very difficult to distinguish the surface $\mathrm{Rh}$ oxide from the bulk Rh oxide using the XANES spectra, thus ignored at the present study. 

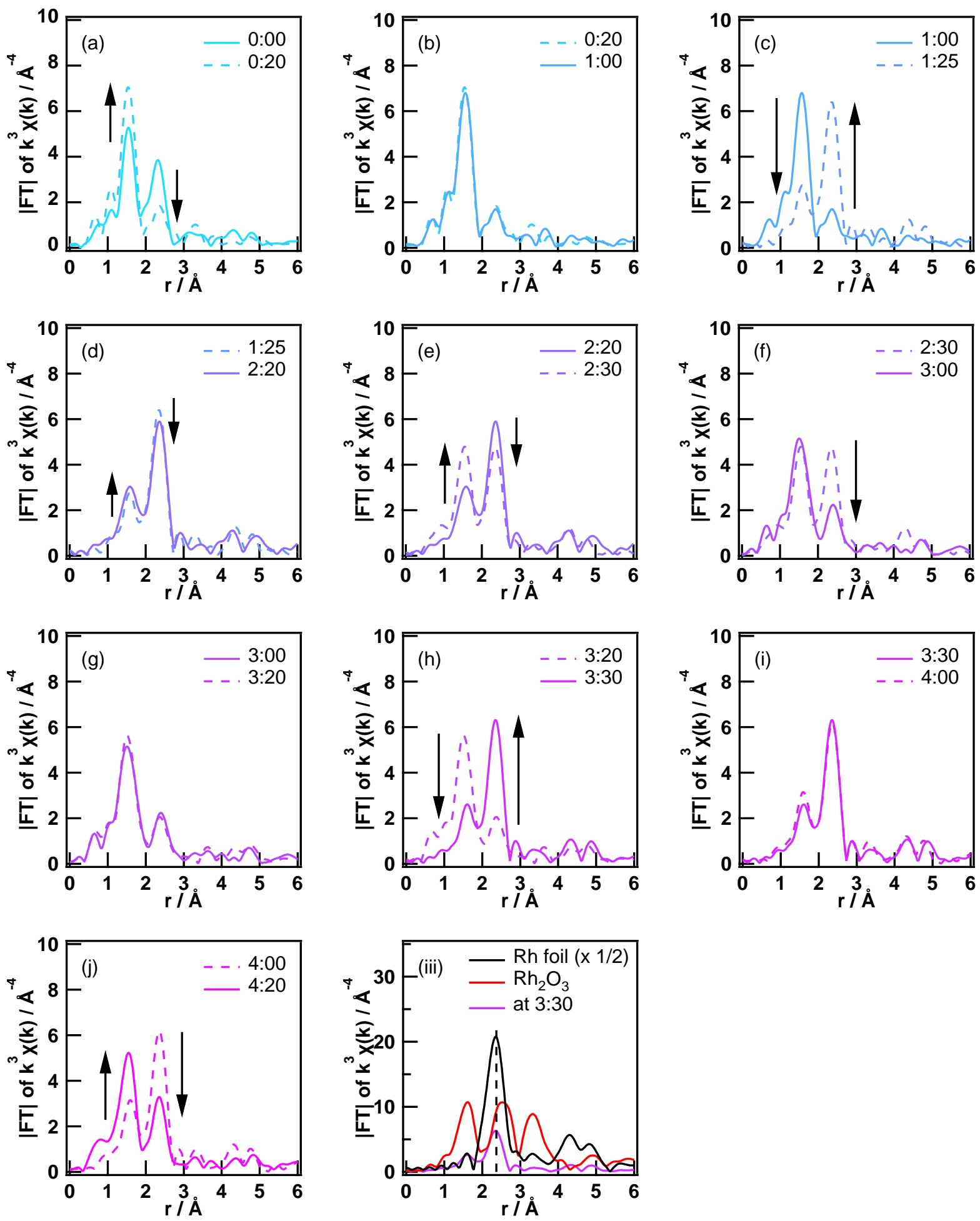

Figure 2. Fourier transform of $\mathrm{Rh} K$-edge EXAFS spectra (phase-uncorrected, $k$-range: $3-13 \AA^{-1}$ ) of 1 wt $\% \mathrm{Rh} / \mathrm{Al}_{2} \mathrm{O}_{3}$ during operando XAS measurement. (a) 0:00-0:20, (b) 0:20-1:00, (c) 1:00-1:25, (d) 1:25-2:20, (e) 2:20-2:30, (f) 2:30-3:00, (g) 3:00-3:20, (h) 3:20-3:30, (i) 3:30-4:00, (j) 4:00-4:20, and (k) Rh metal foil, $\mathrm{Rh}_{2} \mathrm{O}_{3}$, and the sample spectrum at 3:30.

During the second lean-rich-lean cycle (2:40-4:20), the redox behavior of the Rh species was essentially identical to that observed during the first lean-rich-lean cycle. In addition, the redox behavior of the $\mathrm{Rh}$ species under the stoichiometric condition apparently depends on whether the previous condition was lean or rich.
The oxidation state of the $\mathrm{Rh}$ species under the stoichiometric condition after the lean condition showed very little change (0:40-1:00 and 3:00-3:20). However, the Rh species were slowly but significantly oxidized under the stoichiometric condition that followed the rich condition (2:00-2:20 and 3:40-4:00). This suggests that the TWCR likely proceeds 
on the surface Rh oxides and/or Rh species that are reduced by $\mathrm{CO}$ and/or $\mathrm{C}_{3} \mathrm{H}_{6}$, even though the surface of the Rh species was oxidized after the lean condition. On the other hand, the almost completely metallic Rh surface under the rich condition is easily oxidized under the stoichiometric condition. These results suggest that both the metal-like and oxide-like $\mathrm{Rh}$ species display catalytic activity in $\mathrm{CO}$ and $\mathrm{C}_{3} \mathrm{H}_{6}$ oxidation and NO reduction, either individually or cooperatively. In this study, no information is available on the adsorbed species. Therefore, we have started to add a DRIFT apparatus to the operando system for this purpose.

The Fourier transform of the Rh K-edge EXAFS spectra of $1 \mathrm{wt} \% \mathrm{Rh} / \mathrm{Al}_{2} \mathrm{O}_{3}$ during operando XAS measurement are shown in Figure 2. In the first period under the leanest condition, the decreases in the intensities of the Rh-Rh scattering peak at around $2.3 \AA$ and the $\mathrm{Rh}-\mathrm{O}$ peak at around $1.5 \AA$ indicate oxidation of Rh species, which was initiated by exposure to the lean condition [(a), 0:00-0:20]. However, a small peak at around $2.3 \AA$ remained under the oxidative atmosphere. This peak may indicate the remaining unoxidized $\mathrm{Rh}$ metallic cores. After the oxidation process, the Rh species showed little change by the end of the first stoichiometric condition [(b), 0:20-1:00]. This is completely consistent with the XANES temporal change. When the catalyst was exposed to the rich condition, the Rh species were abruptly reduced to the metallic state [(c), 1:00-1:25]. However, the Rh-O scattering peak at around $1.5 \AA$ remained unchanged under the rich and second stoichiometric conditions [(d), 1:25-2:20]. This peak can be explained by the existence of remaining $\mathrm{Rh}_{2} \mathrm{O}_{3}$ cores and/or metal-support interactions at the $\mathrm{Rh}-\mathrm{Al}_{2} \mathrm{O}_{3}$ interface. The introduction of a lean atmosphere again caused rapid [(e), $2: 20-2: 30$ ] and then gradual oxidation [(f), 2:30-3:00] of Rh species. It is noteworthy that the $\mathrm{Rh}-\mathrm{O}$ scattering peak at around $1.5 \AA$ is relatively stable, but the $\mathrm{Rh}-\mathrm{Rh}$ peak decreased significantly. This behavior is well correlated with the gradual increase in the amount of $\mathrm{NO}_{\mathrm{x}}$ in the eluent gas (Figure 1, 2:20-2:30), the subsequent relatively stable detection of $\mathrm{NO}_{\mathrm{x}}$ species (Figure 1, 2:30-3:00), and the corresponding temporal variation of the XANES spectra. We intended primarily to clarify the dynamic behavior of Rh species during the TWCR using XAS as a probe. However, from a different perspective, the reaction results observed using the micro GC, $\mathrm{NO}_{\mathrm{x}}$ meter, and Q-Mass spectrometer are also probes for the $\mathrm{Rh}$ species. Thus, the increase in the amount of $\mathrm{NO}_{\mathrm{x}}$ species (Figure 1, 2:20-2:30) determined using GC and XAS measurements, which are correlated with oxidation of the Rh species, indicates more precisely the oxidation of the surface $\mathrm{Rh}$ species. A kinetic approach toward understanding this behavior is discussed later. The third stoichiometric condition did not induce any significant changes in the Rh species [(g), 3:00-3:20], but the second rich condition again initiated rapid reduction of the $\mathrm{Rh}$ species [(h), 3:20-3:30]. The Rh species were stable by the end of the fourth stoichiometric condition [(i), 3:30-4:00] and oxidized under the last lean condition [(j), 4:00-4:20]. The complete profile of the Rh $K$-edge EXAFS spectra of $1 \mathrm{wt} \% \mathrm{Rh} / \mathrm{Al}_{2} \mathrm{O}_{3}$ is provided in the Supporting Information (Figure S9).

\section{DISCUSSION}

4.1. Comprehensive interpretation in chronological order. The first lean condition $(0: 00-0: 40)$ and the first stoichiometric condition (0:40-1:00) Before the feed gas was introduced, the XANES and EXAFS spectra the very beginning
(Figures 1 and 2) suggest that the Rh species exist in a partially reduced state. It is evident from the GC profile (Figure 1) that the $\mathrm{N}_{2}$ production at the second sampling point $(0: 03)$ was significantly larger than that at the following ones. This implies that the Rh species had a metallic surface, which would exhibit high catalytic activity in the NO reduction reaction but was instantly oxidized under the lean condition. The XANES and EXAFS spectra of the Rh species after the reaction did not show any remarkable change for successive $10 \mathrm{~min}$. The apparent NO reduction activity abruptly changed within 3 min as the feed gas composition changed at 0:20 and 0:40. For example, in the $\mathrm{NO}_{\mathrm{x}}$ profile, it is possible to identify an instant decrease in the detected $\mathrm{NO}_{\mathrm{x}}$ species, which finished in about 2 min around 0:20. This point will be discussed in the next section. Under the first stoichiometric condition, the XANES and EXAFS spectra showed no change, but the $\mathrm{N}_{2}$ production rate reached almost $100 \%$, as expected. To summarize, the $\mathrm{Rh}$ species with a partially reduced surface were oxidized at the very beginning and remained unchanged in this period.

The first rich condition (1:00-2:00) and the second stoichiometric condition (2:00-2:20) As the atmosphere changed to the rich condition at 1:00, the Rh species were dramatically reduced to their metallic state. However, the NO reduction activity changed very little. This suggests that under rich conditions, the surface of the Rh species must be metallic, which suggests at least two different hypotheses on the structure of the Rh species. The first hypothesis is that the surface was already metallic under the first stoichiometric condition, but the inside of most of the Rh species was oxide-like; i.e., most of the $\mathrm{Rh}$ species existed as $\mathrm{Rh}_{2} \mathrm{O}_{3}$ with a thin $\mathrm{Rh}$ metallic layer, which was effective for NO reduction. This hypothesis is consistent with the XANES spectra and Fourier transforms of the EXAFS spectra observed at 1:00 and 1:25. Note that a small scattering peak at around $1.5 \AA$ (Rh-O) was visible throughout the experiment. The second hypothesis is that the surface was nearly oxide-like at 1:00 and almost metallic at $1: 25$, but both Rh species were effective in catalyzing the reduction of NO under the present conditions. However, the drastic decrease of the NO reduction activity at the beginning of the reaction implies the importance of Rh surface state. We guess the second hypothesis is improbable under the present condition at this time, but we will examine this hypothesis in the near future. After 1:20, $\mathrm{N}_{2}$ production was maintained at a nearly steady state, but $\mathrm{CO}_{2}$ production decreased slightly, and remaining $\mathrm{CO}$ was also observed. It is impossible to interpret this phenomenon quantitatively and only in the framework of the TWCR. Therefore, the WGSR is considered to explain these observations, as described in the Supporting Information.

The second lean condition (2:20-3:00) and the third stoichiometric condition (3:00-3:20) Under the second lean condition, the Rh species were oxidized in two steps. The Fourier transforms of the EXAFS spectra at 2:20, 2:30, and 3:00 show a rapid increase in the intensity of the $\mathrm{Rh}-\mathrm{O}$ peak and decrease in the intensity of the Rh-Rh peak in the first step. Subsequently, the intensity of the Rh-Rh peak decreases with a small change in the Rh-O peak. These observations imply that the Rh species were oxidized on the surface (the first step) and later in the bulk (the second step). An interesting phenomenon is observed in the $\mathrm{GC}$ and $\mathrm{NO}_{\mathrm{x}}$ profiles, i.e., a relatively slow decrease in the production of $\mathrm{N}_{2}$ (2:20-2:40). This point will be discussed later. Under the most oxidative atmosphere (2:40-3:00), the rate of $\mathrm{N}_{2}$ production successively decreased to about $60 \%$, which is slightly lower than the rate under the 
first lean condition. We speculate that this is a result of a reduction in the specific surface area of the Rh species via the well-known aggregation process under rich conditions. When the atmosphere returned to the stoichiometric condition (3:00$3: 20)$, the Rh species remained unchanged but exhibited good NO reduction catalytic activity. The activity in this period was the same as that under the first stoichiometric condition on the way from lean to rich conditions.

The second rich condition (3:20-3:40) and the fourth stoichiometric condition (3:40-4:00) After the feed gas was switched to the rich condition again, the $\mathrm{Rh}$ species were rapidly reduced to the metal-like state within $10 \mathrm{~min}$. CO was detected in the Q-Mass spectrum, and $\mathrm{H}_{2}$ gas was observed again. This indicates that the surface of the Rh species had been reduced and the WGSR had occurred, as in the first rich condition. The processes taking place under the fourth stoichiometric condition were the same as those under the second stoichiometric condition on the way from the rich to lean conditions, i.e., gradual surface oxidation of the Rh species. During this period, $\mathrm{NO}$ was quantitatively reduced to $\mathrm{N}_{2}$.

The third lean condition (4:00-4:20) Under the final lean condition, the $\mathrm{N}_{2}$ production rate gradually decreased to $60 \%$, the same level as under the second lean condition. This implies that Rh agglomeration occurred only under the first rich condition and no longer occurred under the present condition. In addition, two different oxidation steps were observed, which can be interpreted as the surface oxidation process and the averaged oxidation state of Rh species.

4.2. Macro kinetics of the surface rearrangement of $\mathbf{R h}$ species. As mentioned in the Results section, the $\mathrm{NO}_{\mathrm{x}}$ profile at every gas composition change exhibited characteristic behavior. When the conditions changed from lean to less lean or stoichiometric ones at $0: 20,0: 40$, and $3: 00$, or from lean to more lean conditions at 2:40, the $\mathrm{NO}_{\mathrm{x}}$ profile showed a discontinuous curve. However, when the conditions changed from stoichiometric to lean at the beginning (0:00), 2:20, and 4:00, the $\mathrm{NO}_{\mathrm{x}}$ profile showed either continuous or sigmoidal curves, as shown in the Supporting Information (Figure S10). First, the discontinuous changes were observed $1 \mathrm{~min}$ and $15 \mathrm{~s}$ after the gas composition was switched. For example, the gas composition was changed at 0:20, and the discontinuous change was observed at around 0:21. Separately, we checked how long it took for the Q-Mass spectrometer to detect the gas switching. We found that it took about $1 \mathrm{~min}$ for the spectrometer to detect a switch in the inlet gas composition both with and without reaction conditions. This indicated that the delay of $1 \mathrm{~min} 15 \mathrm{~s}$ at the $\mathrm{NO}_{\mathrm{x}}$ meter must have been due to the changes in the internal volume from the gas mixer to the detector. Thus, no induction period existed at each discontinuous change. On the other hand, the continuous behavior after the gas composition changes at 2:20 and 4:00 appeared completely different from the above behavior. The initial change was gradual and took about $10 \mathrm{~min}$ to complete. As the $\mathrm{NO}_{\mathrm{x}}$ profile reflects the catalytic activity of NO reduction, it must be related to the properties of the catalytic sites, i.e., the surface $\mathrm{Rh}$ species. Thus, the $\mathrm{NO}_{\mathrm{x}}$ profile can be regarded as an indicator of the oxidation ratio of surface $\mathrm{Rh}$ species. On the basis of this assumption, we tried to interpret the surface rearrangement of Rh species by borrowing an idea from phase transition or particle formation studies.

Kinetics of particle formation The mechanism of particle formation has been extensively studied in various fields relat- ed to crystallography in every possible phase, namely, solidsolid, solid-liquid, and solid-gas. For example, the JohnsonMehl-Avrami-Erove'ev equation, or, more simply, Avrami equation $^{27-29}$ is a famous interpretation of particle formation in the solid-state reaction. On the other hand, the Finke-Watzky equations in either two steps ${ }^{30}$ or four steps ${ }^{31}$ are common explanations of nanoparticle formation in the liquid phase. The relationship between the Avrami and Finke-Watzky equations has been extensively discussed by Finke et al. and Skrdla et al. ${ }^{32-34}$ If the $\mathrm{NO}_{\mathrm{x}}$ concentration in the eluent gas is an indicator of the oxidation degree of the surface of the Rh species, it must be possible to apply the kinetic models discussed above to the $\mathrm{NO}_{\mathrm{x}}$ profile.

Surface rearrangement of $\mathrm{Rh}$ species Figure 3 shows the (inverted) $\mathrm{NO}_{\mathrm{x}}$ profiles and fitted curves in the important gas switching regions. The inverted $\mathrm{NO}_{\mathrm{x}}$ profile plots the values as $1000-\mathrm{NO}_{\mathrm{x}}(\mathrm{ppm})$. Basically, we assume that $\mathrm{NO}$ is reduced on the metal-like Rh site directly or indirectly. The reduction rate of NO can be assumed to be proportional to the number of metal-like $\mathrm{Rh}$ sites available for catalysis (i.e., on the surface). The inverted $\mathrm{NO}_{\mathrm{x}}$ profile is the reduction rate of $\mathrm{NO}$ and must be proportional to the number of catalytically active metal-like $\mathrm{Rh}$ sites. Then, we hypothesize that the inverted $\mathrm{NO}_{\mathrm{x}}$ profile can be proportional to the concentration of $\mathrm{Rh}^{0}$ species. The pseudo-first-order kinetic model (i.e., a simple exponential model, where $[A]_{\mathrm{t}}$ : concentration of $\mathrm{Rh}^{3+}$ at time $t$; $[A]_{\mathrm{d}}$ : difference between concentrations of $\mathrm{Rh}^{3+}$ in the initial and final states; $t$ : time; $t_{\text {offset }}$ : time offset; $\tau$ : time constant; $[A]_{1}$ : offset of concentration of $\mathrm{Rh}^{3+}$ in the final states) was utilized to fit the inverted $\mathrm{NO}_{\mathrm{x}}$ decay profiles [Figure 3(A), (B), (D), and (E)].

$$
[A]_{\mathrm{t}}=[A]_{\mathrm{d}} \exp \left(-\left(\frac{t-t_{\text {offset }}}{\tau}\right)\right)+[A]_{1}
$$

For Figure 3(A), (B), and (E), the oxide-like surface Rh species were exposed to richer gas. These results imply that the surface oxide-like $\left(\mathrm{Rh}_{2} \mathrm{O}_{3}\right.$-like) $\mathrm{Rh}$ species was reduced randomly, and the reaction followed the pseudo-first-order kinetic model as a function of the concentration of the surface $\mathrm{Rh}_{2} \mathrm{O}_{3}$ species. The curve shown in Figure 3(D) similarly fitted this kinetic model. This indicates that metallic surface Rh species were oxidized randomly. On the other hand, it is obviously impossible to apply the pseudo-first-order kinetic model to the inverted $\mathrm{NO}_{\mathrm{x}}$ profiles when the catalysts were exposed to lean gas conditions. Under these conditions, we applied the Finke-Watzky equation formulated from the two-step nanoparticle formation mechanism, as described below ( $[A]_{\mathrm{t}}$ : concentration of $\mathrm{Rh}^{0}$ at time $t ;[A]_{0}$ : difference between concentrations of $\mathrm{Rh}^{0}$ in the initial and final states; $[A]_{1}$ : offset of concentration of $\mathrm{Rh}^{0}$ in the final state; $t$ : time; $k_{1}$ : rate constant for $\mathrm{Rh}^{0} \rightarrow \mathrm{Rh}^{3+} ; k_{2}$ : rate constant for $\left.\mathrm{Rh}^{0}+\mathrm{Rh}^{3+} \rightarrow 2 \mathrm{Rh}^{3+}\right)$, and obtained well-fitted results [Figure 3(C) and (F)].

$$
[A]_{\mathrm{t}}=\frac{\frac{k_{1}}{k_{2}}+[A]_{0}}{1+\frac{k_{1}}{k_{2}[A]_{0}} \exp \left(\left(k_{1}+k_{2}[A]_{0}\right) t\right)}+[A]_{1}
$$

This implies that an oxide-like nucleus was first generated on the surface of the metallic Rh species under the lean condition (nuclear generation), and oxygen atoms were successively consumed around the oxide-like $\mathrm{Rh}$ species (autocatalytic reaction). 

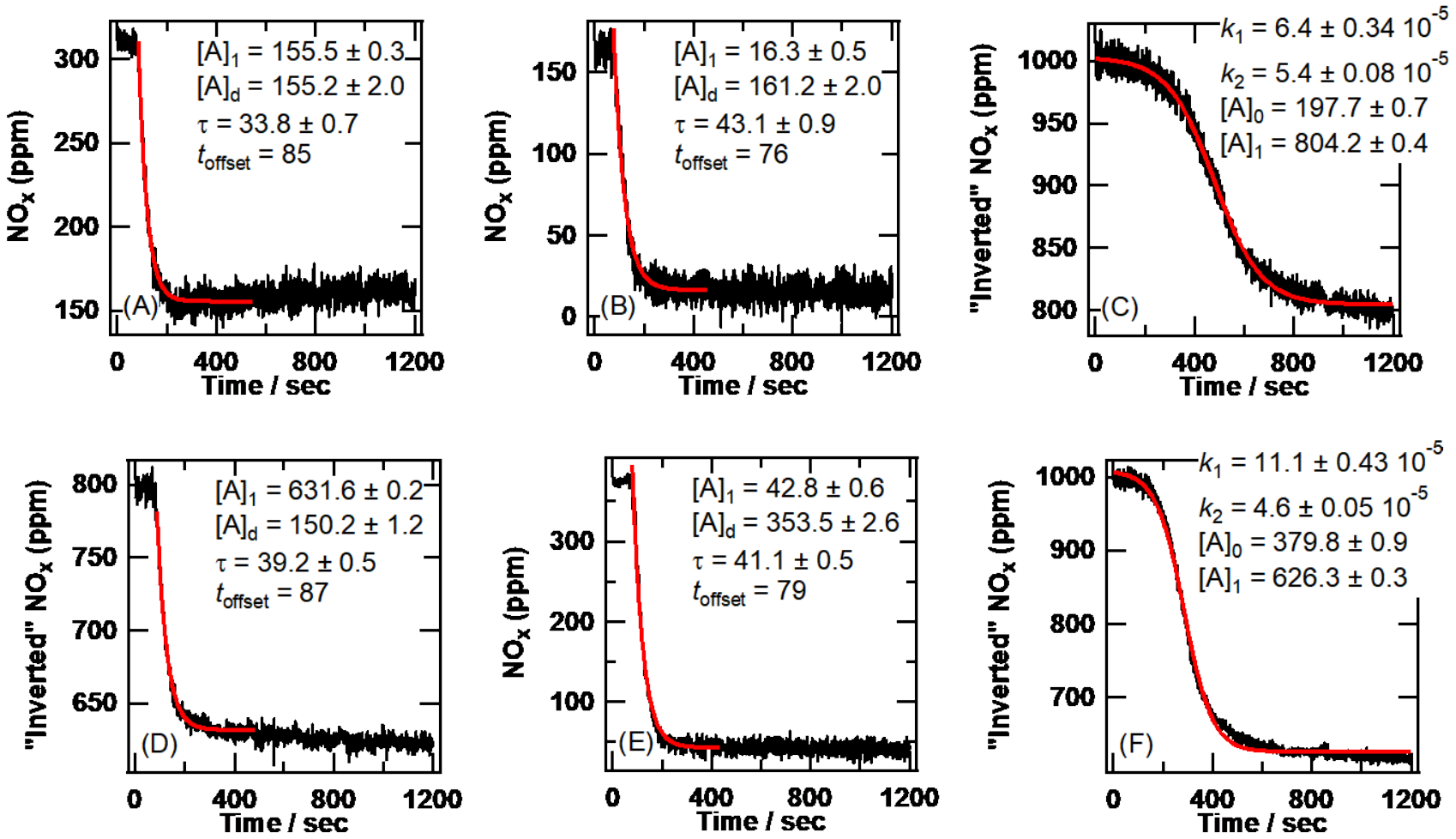

Figure 3. (Inverted) $\mathrm{NO}_{\mathrm{x}}$ profiles with fitted curve based on pseudo-first-order kinetics or Finke-Watzky two-step particle formation mechanism in gas switching regions. (Red lines are fitted curves.) The time axis is defined as the elapsed time from (A) 0:20, (B) 0:40, (C) 2:20, (D) 2:40, (E) 3:00, and (F) 4:00.

After $600 \mathrm{~s}$, the latter region exhibited a gradual decrease in the inverted $\mathrm{NO}_{x}$ profile. This behavior of the $\mathrm{Rh}_{2} \mathrm{O}_{3}$-like species might be related to Ostwald ripening, which might be understood as a random walk of oxygen atoms on the surface of the Rh species. The combination of the two-step FinkeWatzky mechanism and the Ostwald ripening process has already been successfully applied to understand the formation mechanism of Ag or Pd nanoparticles in the liquid phase by Harada et al. ${ }^{35-36}$ However, this behavior has minimal significance in our case and can be simply ignored. It is important to note that there is a significant difference between the oxidation processes of a metallic surface and the reduction processes of an oxidized surface, as discussed above.

\subsection{Schematic view of dynamic behavior of $\mathrm{Rh}$ species.}

The dynamic behavior of Rh species when the gas composition is switched are summarized in Scheme 2. We assumed that the sizes of the Rh nanoparticles were almost unchanged because the intensities of the Fourier transforms of the EXAFS spectra at 1:25 (the first rich condition) and at 3:30 (the second rich condition) were similar. Considering the reduction process of Rh species, the surface of the oxide-like Rh species was easily reduced to the metallic state swiftly and randomly. On the other hand, in the oxidation process of Rh species, surface oxidation of $\mathrm{Rh}$ species proceeded via random and autocatalytic growth by oxide-like Rh site generation.

This schematic was deduced on the basis of examination of the outlet gas with a micro GC, a $\mathrm{NO}_{\mathrm{x}}$ meter, and a Q-Mass spectrometer, and also from the results of the operando XAS study. Thus, this study demonstrates the importance of the surface state of Rh species during the TWCR. As real automobile exhaust contains many different gases such as $\mathrm{H}_{2} \mathrm{O}, \mathrm{H}_{2}$, various $\mathrm{HCs}, \mathrm{CO}, \mathrm{CO}_{2}, \mathrm{NO}$, or $\mathrm{NO}_{2}$, the present observations cannot be used to deduce the real TWCR conditions. However, this study provides clear insights that surface rearrangement of $\mathrm{Rh}$ can have a great impact on real TWCs, albeit on much smaller space and time scales.

Scheme 2. Redox behavior of Rh species when the gas composition is switched.

(a) Reduction process

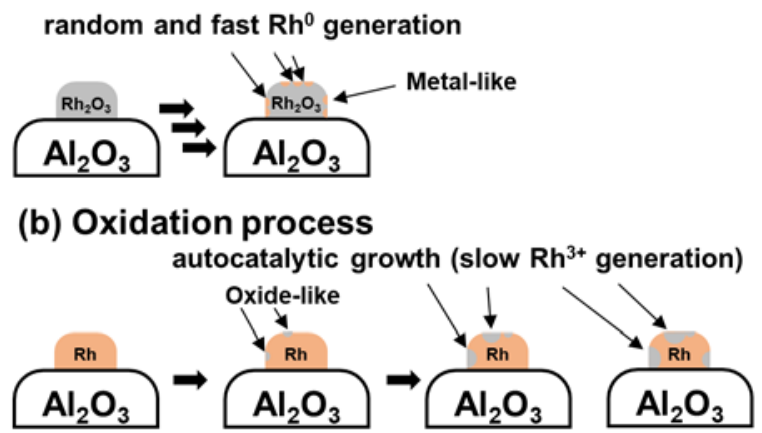

\section{CONCLUSION}

In this study, an operando XAS measurement system equipped with a micro GC, $\mathrm{NO}_{\mathrm{x}}$ meter, and Q-Mass spectrometer was successfully built at a public XAS beamline, BL01B1, at SPring-8. Operando spectroscopy itself is not new. However, most operando studies have used only one or two additional probes under conditions that differ significantly from typical laboratory conditions. In our work, four probes are fully integrated (XAS, micro-GC, $\mathrm{NO}_{\mathrm{x}}$ meter, Q-Mass spectrometer), providing complementary data useful for gaining deep insight 
into the nature of heterogeneous catalysts. Using this system, we directly observed the dynamic behavior of Rh species in 1 wt $\% \mathrm{Rh} / \mathrm{Al}_{2} \mathrm{O}_{3}$ under relatively idealized conditions. Consequently, we estimated the dynamics of surface and bulk Rh species during the TWCR by quantitative analysis obtained with various detectors operando. Of course, there are an enormous number of studies on the catalytic performance, mechanism, or degradation of TWCs that used various techniques independently. However, such studies have usually been performed under significantly different conditions, which sometimes made unified understanding difficult. In this study, we performed a catalytic performance test, investigated the catalytic mechanism in terms of surface chemistry, and even examined part of the degradation mechanism simultaneously. The present operando data obtained under the exactly same condition enables us to interpret them consistently, and this work is the first quantitative evaluation of surface rearrangement of Rh species using model automobile exhaust gases at the laboratory level. Although the present relatively idealistic condition was not so close to the real automobile exhaust condition, we believe this study sheds light on the fundamental dynamic behavior of $\mathrm{Rh}$ species in the $\mathrm{Rh} / \mathrm{Al}_{2} \mathrm{O}_{3}$ catalyst under near-stoichiometric conditions.

\section{ASSOCIATED CONTENT}

Supporting Information. TWCR at a laboratory, the temperature profile, a series of XANES and EXAFS spectra, selected $\mathrm{NO}_{\mathrm{x}}$ profiles during the operando XAS measurement, discussion of WGSR, and TEM images. This material is available free of charge via the Internet at http://pubs.acs.org.

\section{AUTHOR INFORMATION}

\section{Corresponding Author}

* tanakat@moleng.kyoto-u.ac.jp (TT)

\section{Notes}

The authors declare no competing financial interest.

\section{ACKNOWLEDGMENT}

This work was performed under the management of the Elements Strategy Initiative for Catalysts \& Batteries (ESICB) supported by the Ministry of Education, Culture, Sports, Science and Technology (MEXT), Japan, as part of the program "Elements Strategy Initiative to Form Core Research Center.” We thank Mr. Kosuke Beppu, Mr. Kazuki Tamai, and Mr. Soichi Kikkawa (Kyoto University), Mr. Yuji Mahara and Mr. Kakuya Ueda (Nagoya University), Mr. Yuichiro Wada (Oita University), and Mr. Shun Hayashi (University of Tokyo) for their assistance with the operando XAS measurements. XAS experiments were performed at a public beamline (BL01B1) at SPring-8 with the approval of JASRI (Proposal Nos. 2016A1025, 2016A1834, 2016B1019, 2016B1405, and 2016B1457).

\section{ABBREVIATIONS}

EXAFS, Extended X-ray Absorption Fine Structure; HCs, Hydrocarbons; Q-Mass Spectrometer, Quadrupole Mass Spectrometer; TWC, Three-Way Catalyst; TWCR, Three-Way Catalytic Reaction; WGSR, Water-Gas Shift Reaction; XANES, X-ray Absorption Near-Edge Structure; XAS, X-ray Absorption Spectroscopy.

\section{REFERENCES}

1. Johnson Matthey, P. L. C., Platinum 2013. 2013.
2. Japan Automobile Manufacturers Association Inc., Statistics on automobile production, sales, ownership, and exports worldwide. http://www.jama.or.jp/world/world/index.html (accessed Jul 7, 2017). 3. Srinivasan, A.; Depcik, C., Review of Chemical Reactions in the NO Reduction by CO on Rhodium/Alumina Catalysts. Catal. Rev. 2010, 52, 462-493.

4. Shimizu, K.; Kawabata, H.; Satsuma, A.; Hattori, T., Formation and Reaction of Surface Acetate on $\mathrm{Al}_{2} \mathrm{O}_{3}$ during NO Reduction by $\mathrm{C}_{3} \mathrm{H}_{6}$. Appl. Catal. B 1998, 19, L87-L92.

5. Simonsen, S. B.; Chorkendorff, I.; Dahl, S.; Skoglundh, M.; Sehested, J.; Helveg, S., Direct Observations of Oxygen-Induced Platinum Nanoparticle Ripening Studied by In Situ TEM. J. Am. Chem. Soc. 2010, 132, 7968-7975.

6. Jozwiak, W. K.; Kaczmarek, E.; Maniecki, T. P.; Ignaczak, W.; Maniukiewicz, W., Reduction Behavior of Iron Oxides in Hydrogen and Carbon Monoxide Atmospheres. Appl. Catal. A 2007, 326, 17-27. 7. Chen, W.; Pan, X.; Bao, X., Tuning of Redox Properties of Iron and Iron Oxides via Encapsulation within Carbon Nanotubes. J. Am. Chem. Soc. 2007, 129, 7421-7426.

8. Chen, W.; Fan, Z.; Pan, X.; Bao, X., Effect of Confinement in Carbon Nanotubes on the Activity of Fischer-Tropsch Iron Catalyst. J. Am. Chem. Soc. 2008, 130, 9414-9419.

9. Chen, W.; Pan, X.; Willinger, M. G.; Su, D. S.; Bao, X., Facile Autoreduction of Iron Oxide/Carbon Nanotube Encapsulates. J. Am. Chem. Soc. 2006, 128, 3136-3137.

10. Dent, A. J.; Diaz-Moreno, S.; Evans, J.; Fiddy, S. G.; Jyoti, B.; Newton, M. A., In Situ Monitoring of Oxide-Supported PlatinumGroup Metal Catalysts by Energy Dispersive EXAFS. Phys. Scripta 2005, 72-75.

11. Evans, J.; Dent, A. J.; Diaz-Moreno, S.; Fiddy, S. G.; Jyoti, B.; Newton, M. A.; Tromp, M., In Situ Structure-Function Studies of Oxide Supported Rhodium Catalysts by Combined Energy Dispersive XAFS and DRIFTS Spectroscopies. AIP Conf. Proc. 2007, 882, 603607.

12. Newton, M. A.; Dent, A. J.; Fiddy, S. G.; Jyoti, B.; Evans, J., Particle Size Effects in $\mathrm{Rh} / \mathrm{Al}_{2} \mathrm{O}_{3}$ Catalysts as Viewed from a Structural, Functional, and Reactive Perspective: the Case of the Reactive Adsorption of NO. J. Mater. Sci. 2007, 42, 3288-3298.

13. Newton, M. A.; Dent, A. J.; Fiddy, S. G.; Jyoti, B.; Evans, J., Combining Diffuse Reflectance Infrared Spectroscopy (DRIFTS), Dispersive EXAFS, and Mass Spectrometry with High Time Resolution: Potential, Limitations, and Application to the Study of NO Interaction with Supported Rh Catalysts. Catal. Today 2007, 126, 64-72.

14. Newton, M. A.; Dent, A. J.; Fiddy, S. G.; Jyoti, B.; Evans, J., Identification of the Surface Species Responsible for $\mathrm{N}_{2} \mathrm{O}$ Formation from the Chemisorption of NO on Rh/Alumina. Phys. Chem. Chem. Phys. 2007, 9, 246-249.

15. Dent, A. J.; Evans, J.; Fiddy, S. G.; Jyoti, B.; Newton, M. A.; Tromp, M., Structure-Performance Relationships of Rh and RhPd Alloy Supported Catalysts using Combined EDE/DRIFTS/MS. Faraday Discuss. 2008, 138, 287-300.

16. Newton, M. A., Applying Dynamic and Synchronous DRIFTS/EXAFS to the Structural Reactive Behaviour of Dilute $\left(\leq 1 \mathrm{wt} \%\right.$ ) Supported $\mathrm{Rh} / \mathrm{Al}_{2} \mathrm{O}_{3}$ Catalysts using Quick and Energy Dispersive EXAFS. Top. Catal. 2009, 52, 1410-1424.

17. Kroner, A. B.; Newton, M. A.; Tromp, M.; Roscioni, O. M.; Russell, A. E.; Dent, A. J.; Prestipino, C.; Evans, J., Time-Resolved, In Situ DRIFTS/EDE/MS Studies on Alumina-Supported Rhodium Catalysts: Effects of Ceriation and Zirconiation on Rhodium-CO Interactions. ChemPhysChem 2014, 15, 3049-3059.

18. Kimmerle, B.; Haider, P.; Grunwaldt, J.-D.; Baiker, A.; Boye, P.; Schroer, C. G., High Throughput Cell for X-ray Absorption Spectroscopy Applied to Study the Effect of $\mathrm{Au}$ on Rh-Catalyzed Partial Oxidation of Methane. Appl. Catal. A 2009, 353, 36-45.

19. Stötzel, J.; Lützenkirchen-Hecht, D.; Frahm, R.; Kimmerle, B.; Baiker, A.; Nachtegaal, M.; Beier, M. J.; Grunwaldt, J. D., Investigation of the Ignition Behaviour of the Noble Metal Catalyzed Catalytic Partial Oxidation of Methane. J. Phys.: Conf. Ser. 2009, 190, 012162. 
20. Grunwaldt, J.-D.; Beier, M.; Kimmerle, B.; Baiker, A.; Nachtegaal, M.; Griesebock, B.; Lutzenkirchen-Hecht, D.; Stotzel, J.; Frahm, R., Structural Changes of Noble Metal Catalysts during Ignition and Extinction of the Partial Oxidation of Methane Studied by Advanced QEXAFS Techniques. Phys. Chem. Chem. Phys. 2009, 11, 8779-8789.

21. Hannemann, S.; Grunwaldt, J.-D.; van Vegten, N.; Baiker, A.; Boye, P.; Schroer, C. G., Distinct Spatial Changes of the Catalyst Structure Inside a Fixed-Bed Microreactor during the Partial Oxidation of Methane over $\mathrm{Rh} / \mathrm{Al}_{2} \mathrm{O}_{3}$. Catal. Today 2007, 126, 54-63. 22. Hannemann, S.; Grunwaldt, J.-D.; Lienemann, P.; Günther, D.; Krumeich, F.; Pratsinis, S. E.; Baiker, A., Combination of Flame Synthesis and High-Throughput Experimentation: The Preparation of Alumina-Supported Noble Metal Particles and Their Application in the Partial Oxidation of Methane. Appl. Catal. A 2007, 316, 226-239.

23. Grunwaldt, J.-D.; Hannemann, S.; Schroer, C. G.; Baiker, A., 2DMapping of the Catalyst Structure Inside a Catalytic Microreactor at Work: Partial Oxidation of Methane over $\mathrm{Rh} / \mathrm{Al}_{2} \mathrm{O}_{3}$. J. Phys. Chem. B 2006, 110, 8674-8680.

24. Grunwaldt, J.-D.; Baiker, A., Axial Variation of the Oxidation State of Pt-Rh/ $\mathrm{Al}_{2} \mathrm{O}_{3}$ during Partial Methane Oxidation in a FixedBed Reactor: An In Situ X-ray Absorption Spectroscopy Study. Catal. Lett. 2005, 99, 5-12.

25. Uruga, T.; Tanida, H.; Yoneda, Y.; Takeshita, K.; Emura, S.; Takahashi, M.; Harada, M.; Nishihata, Y.; Kubozono, Y.; Tanaka, T.; Yamamoto, T.; Maeda, H.; Kamishima, O.; Takabayashi, Y.; Nakata, Y.; Kimura, H.; Goto, S.; Ishikawa, T., The XAFS Beamline BL01B1 at SPring-8. J. Synchrotron Rad. 1999, 6, 143-145.

26. Ravel, B.; Newville, M., ATHENA, ARTEMIS, HEPHAESTUS: Data Analysis for X-ray Absorption Spectroscopy Using IFEFFIT. $J$. Synchrotron Rad. 2005, 12, 537-541.

27. Avrami, M., Kinetics of Phase Change. I General Theory. J. Chem. Phys. 1939, 7, 1103-1112.

28. Avrami, M., Kinetics of Phase Change. II Transformation-Time Relations for Random Distribution of Nuclei. J. Chem. Phys. 1940, 8 , 212-224.

29. Avrami, M., Granulation, Phase Change, and Microstructure Kinetics of Phase Change. III. J. Chem. Phys. 1941, 9, 177-184.

30. Watzky, M. A.; Finke, R. G., Transition Metal Nanocluster Formation Kinetic and Mechanistic Studies. A New Mechanism When Hydrogen Is the Reductant: Slow, Continuous Nucleation and Fast Autocatalytic Surface Growth. J. Am. Chem. Soc. 1997, 119, 10382-10400.

31. Besson, C.; Finney, E. E.; Finke, R. G., A Mechanism for Transition-Metal Nanoparticle Self-Assembly. J. Am. Chem. Soc. 2005, 127, 8179-8184.

32. Finney, E. E.; Finke, R. G., Fitting and Interpreting TransitionMetal Nanocluster Formation and Other Sigmoidal-Appearing Kinetic Data: A More Thorough Testing of Dispersive Kinetic vs ChemicalMechanism-Based Equations and Treatments for 4-Step Type Kinetic Data. Chem. Mater. 2009, 21, 4468-4479.

33. Skrdla, P. J., Comment on "Fitting and Interpreting TransitionMetal Nanocluster Formation and Other Sigmoidal-Appearing Kinetic Data: A More Thorough Testing of Dispersive Kinetic vs ChemicalMechanism-Based Equations and Treatments for 4-Step Type Kinetic Data”. Chem. Mater. 2010, 22, 2685-2686.

34. Finney, E. E.; Finke, R. G., Reply to Comment on "Fitting and Interpreting Transition-Metal Nanocluster Formation and Other Sigmoidal-Appearing Kinetic Data: A More Thorough Testing of Dispersive Kinetic vs Chemical-Mechanism-Based Equations and Treatments for 4-Step Type Kinetic Data”. Chem. Mater. 2010, 22, 2687-2688.

35. Harada, M.; Ikegami, R., In Situ Quick X-ray Absorption Fine Structure and Small-Angle X-ray Scattering Study of Metal Nanoparticle Growth in Water-in-Oil Microemulsions during Photoreduction. Cryst. Growth Des. 2016, 16, 2860-2873.

36. Harada, M.; Kizaki, S., Formation Mechanism of Gold Nanoparticles Synthesized by Photoreduction in Aqueous Ethanol Solutions of Polymers Using In Situ Quick Scanning X-ray Absorption Fine Structure and Small-Angle X-ray Scattering. Cryst. Growth Des. 2016, 16, 1200-1212. 


\section{Table of Contents}

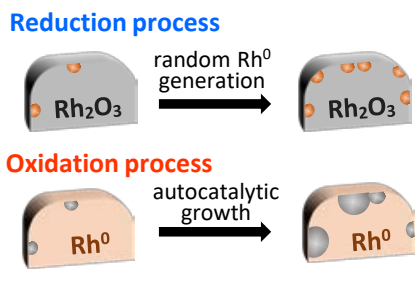

